Fragmented Tasmania: the transition from Rodinia to Gondwana

D. H. MOORE, P. G. BETTS AND M. HALL

School of Earth, Atmosphere and Environment, Monash University, Clayton, VIC 3800, Australia

e-mail: david.moore@monash.edu

\title{
SUPPLEMENTARY PAPERS
}

Australian Journal of Earth Sciences (2015) 62,

http://dx.doi.org/10.1080/08120099.2014.966757

Copies of Supplementary Papers may be obtained from the Geological Society of Australia's website (www.gsa.org.au), the Australian Journal of Earth Scienecs website (www.ajes.com.au) or from the National Library of Australia's Pandora archive (http://nla.gov.au/nla.arc-25194).

\section{SUPPLEMENTARY PAPER}

Figure A1 Combined time-space plot (Figure 2). 


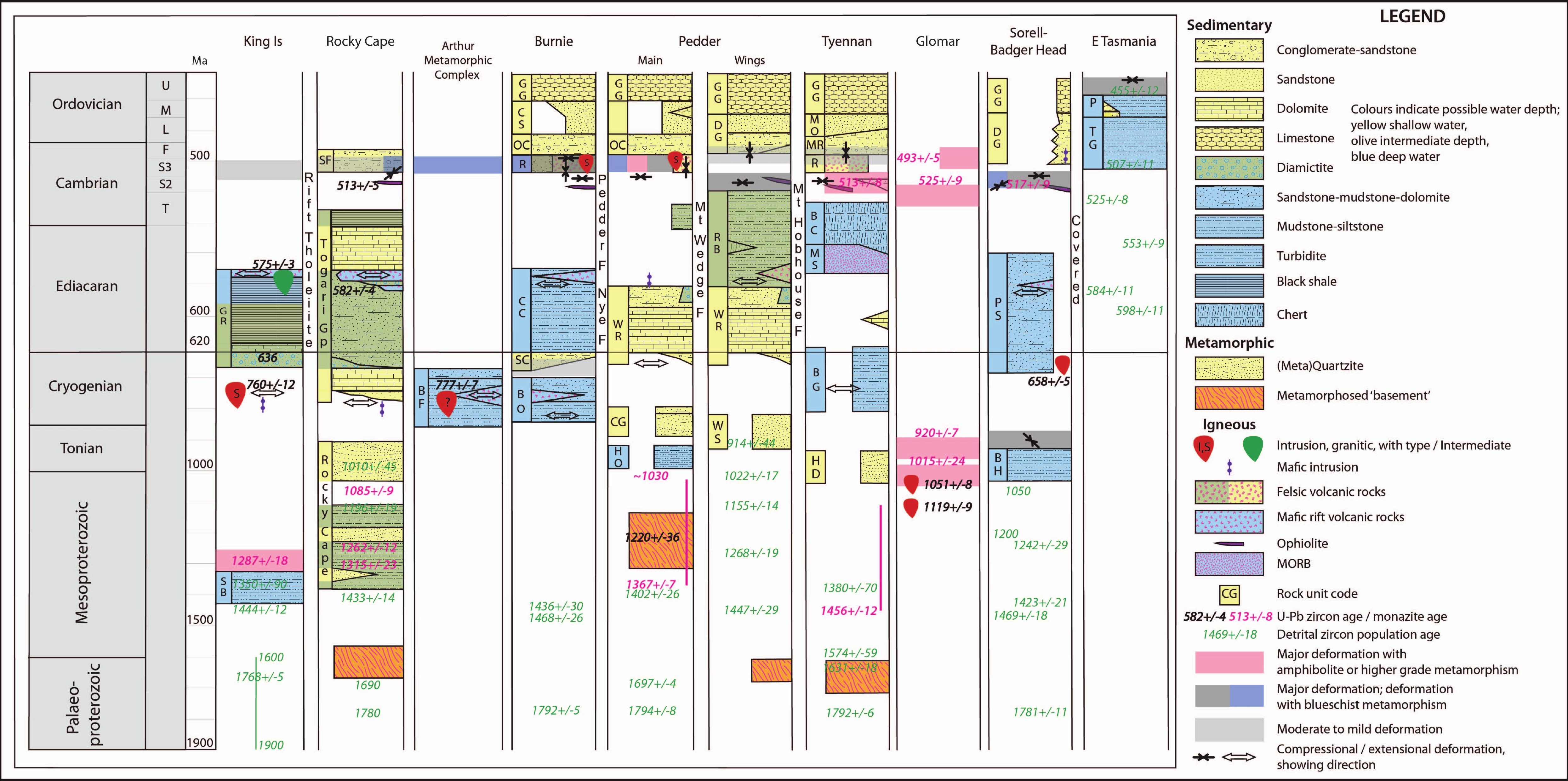

